\title{
The Problem of Labor Loss under the Background of Rural Revitalization and Countermeasure Analysis
}

\author{
Shidong Zhang \\ School of Economics and Management, Zhejiang Ocean University, Zhoushan 316022, Zhejiang, China
}

\begin{abstract}
In the Fifth Plenary Session of the Nineteenth Central Committee of the recent past, it was pointed out that in order to achieve comprehensive prosperity and eliminate poverty completely, my country must focus on the "three rural issues" and implement the rural revitalization strategy. As a large agricultural country, our country has a large rural population, and the rural land is relatively vast. Therefore, if our country wants to achieve full prosperity, it must promote the implementation of the rural revitalization strategy, so as to enable the rapid development of rural areas. Looking at this problem from a micro perspective, there are still certain restrictions and constraints, such as the serious loss of rural labor, resulting in an empty nest phenomenon, or the serious aging of the rural population. These reasons all restrict rural development and rural modernization. The advancement of urbanization. This article mainly focuses on the problem of rural labor loss under the current rural revitalization strategy, and further proposes countermeasures and suggestions to solve the problem in response to this phenomenon, in order to provide a certain reference and reference for rural development.
\end{abstract}

Keywords: Rural revitalization, Labor loss, Youth development.

\section{Research Background and Significance}

\subsection{Research Background}

As a typical agricultural country, my country has a relatively large rural population and relatively large rural land. Chinese society is a rural society. The essence of China's core culture is rural culture. Therefore, it is very important to revitalize and develop rural areas. At the Fifth Plenary Session of the 19th Central Committee held not long ago, it was once again emphasized that we must take the rural revitalization strategy as the focus of the work of the party and the government, and put forward specific requirements for rural revitalization [1]. This has laid the foundation for China to achieve an all-round well-off, eradicate poverty, and fight a tough battle against poverty.

The issue of "agriculture, rural areas, and farmers" has always been a concern of our country. In 19 years, my country's rural development has made great progress and has improved significantly, but there are still many phenomena of unbalanced development, such as the east and the west. There is a big gap in the development of regional rural economy, and there are also big differences in the process of urbanization and modernization. In 2018, the Chinese government announced the "Several Opinions of the State Council on the Implementation of the Rural Revitalization Strategy", which pointed out that in order to rejuvenate the countryside, the development of rural areas can only be done by focusing on labor and characteristic development in order to revitalize talents and funds. Although human civilization continues to develop, the decline of rural areas is worldwide and an inevitable result of development. The British Industrial Revolution is one of the reasons for the prosperity of civilization, but it will harm the interests of farmers and the middle and lower classes. In the seventeenth century, Britain became one of the most prosperous powers in the world. At the time, the world called it the "empire that never sets in the sun." With the continuous development of Britain, the scope of its colonies expanded rapidly, and British textiles gained a lot. In the market space, the ruler squeezed the peasants and the middle and lower classes for the benefit. Most of the farmland became pasture, and the peasants were squeezed into workers in desperation. This is also the substantial reason for the decline of the British rural economy. Since the twentieth century, China's rural areas have undergone earth-shaking changes, especially in the western rural areas. The decline of the western rural areas is an undeniable fact. Reform and opening up have enabled my country to make great progress and gain more material wealth, but at the same time, it has also made major changes to China's social structure, social class, ideology, and natural outlook. Across the country, 240 million peasants migrated to cities to work, which increased the population flow between urban and rural areas, and caused large fluctuations in the population ratio and population age ratio between urban and rural areas. More young and middle-aged laborers migrated to cities, resulting in The problem of labor loss in rural areas has led to the phenomenon of empty nests in rural areas and the increase of left-behind children.

\subsection{Research Significance}

First, studying this topic can better implement the strategy of rural revitalization and rural development, and fundamentally solve the "three rural issues" better. The central government's decision to implement the strategy of revitalizing the countryside is to solve the problem of underdeveloped rural areas in most rural areas, underdeveloped agriculture, and poor farmers. Development and progress can be achieved by adhering to the development concepts of reform and opening up, coordinated development, innovative awareness, green development, and shared resources.

Second, it is possible to better develop the countryside and 
improve the phenomenon of the loss of rural labor, so that the social, economic and other aspects of the countryside can be developed and improved, so as to better guarantee the food security of our country. The 19th National Congress of the Communist Party of China also put forward the view that the actual implementation of the strategy of rural revitalization is essentially to allow the Chinese people to hold their own rice bowls firmly and not let go. Since ancient times, China has been both an agricultural country and a country with a large population. With a large population and food for the people, the most fundamental and most important thing for a country is food security. General Secretary Xi also said that in order to keep the Chinese people's rice bowl firmly in their own hands, it is necessary to make sufficient progress in agricultural production, and rural rejuvenation is also to make the grain harvest, agricultural development, and farmers happy.

\section{Problem Analysis}

\subsection{Among the "Three Rural" Issues, the "Farmer" Issue is Prominent, and the Labor Issue is Significant}

The problem of population aging in rural areas in China is becoming more and more serious, the quality of the labor force is generally low, and the level of education is generally low [2]. In the country's rural areas, the proportion of people over the age of 60 to the total village population exceeds the social standard [3]. Among them, rural aging in Northeast China is the most serious, followed by North China. According to the "China Human Capital Report" issued by the Central University of Finance and Economics, the average age of my country's overall labor force is 37.8 years old, and the labor force with a technical secondary school or higher education is only 17.6 percent. It is not just the labor force in rural areas, but from my personal point of view, if we only look at the labor force index in rural areas, the proportion of the aging labor force will only be greater, and the level of education will also be lower.

\subsection{Urban-Rural Separation, the Gap between Urban and Rural Areas Is Growing, and the Labor Force Continues to Drain}

The gap between urban and rural areas continues to widen, and young and middle-aged laborers continue to flow from the countryside to the cities, which has led to the phenomenon of urban migrant workers and the emergence of empty nests in rural areas and the emergence of left-behind children. Among them, my personal opinion is that the main reasons for the loss of rural labor to the cities are still divided into the following points:

First, the family's overall income is low, and even cannot make ends meet [4]. Today when prices are soaring, prices in rural areas are also rising. For farmers, family life needs expenditure. After they have children, they need to continue to spend money from birth. Coupled with children's marriage and marriage, it is difficult to rely solely on land for planting. So much expense.
Second, the development of rural areas has been lagging behind, and the attractiveness of cities has increased. After the reform and opening up, the state has increased its investment in rural areas in an attempt to narrow the gap between urban and rural areas. However, on the whole, the four characteristics of rural areas: "stupid", "poor", "weak" and "private" have not been fundamentally obtained. Solve [5]. For example, in rural areas, especially in remote areas, the level of education of the rural population is still low, and spiritual and cultural life is still poor; the overall development of rural areas is relatively lagging, and price increases have led to a slow increase in the overall economic level of rural areas; rural health and medical infrastructure is still weak. The social security system needs to be improved. In the cities, there are more employment opportunities, higher salaries, a more comfortable living environment and more convenient transportation methods than in the countryside, which has resulted in the loss of rural labor, especially the loss of young and middle-aged labor to the cities[6].

Third, the production efficiency is low. Agricultural management usually has a long production cycle, seasonality of agricultural products, and is relatively affected by natural conditions, and its business model is relatively scattered, and the risk of agricultural production is relatively high, but the income is low, and the social status is low. As a result, farmers' enthusiasm for farming has gradually declined.

\section{The Impact of Labor Transfer}

\subsection{Positive Influence}

First, the transfer of labor from rural areas to cities has promoted the development of cities to a certain extent and solved the shortcomings of insufficient urban labor [7]. A large number of rural surplus laborers continue to pour into cities from rural areas, replenishing fresh blood and sufficient labor force for cities, thus speeding up the process of urban development.

Second, it increased the income of rural surplus labor to a certain extent, thereby promoting the economic development of local rural areas [8]. Lewis' dual economic theory once proposed that the phenomenon of the transfer of rural labor to the city itself is a manifestation and sign of economic development. The rural labor force moved to the city, obtained a large number of employment opportunities and higher salaries, and thus obtained higher income [9]. However, because the level of urbanization and industrialization in some northwestern regions is not developed enough, and the traditional agricultural economy has not been completely converted, the secondary and tertiary industries in cities and towns are not strong enough. Therefore, the rural labor force in some northwestern regions is mainly Flow into the eastern coastal cities to increase their income [10].

Third, it has improved the quality and vision of the rural labor force. The surplus labor force from the countryside has been pouring into the cities from the countryside. Through work and study for a period of time, it has broadened its horizons, 
and at the same time improved its own quality, mastered some professional knowledge and skills, so as to obtain better Development.

Fourth, the transfer of labor has accelerated the process of agricultural modernization. Under the conditions of a free economy, the average profit rate of agricultural production must be increased to the level of the average profit rate of the whole society [11], otherwise no one in a large agricultural country like China is willing to engage in agricultural production, which is important for my country's food security. There is a huge threat, but this inherent driving force promotes the rapid development of agriculture in order to realize modernization to increase productivity and product rates.

\subsection{Negative Influence}

First, the demographic structure of the rural society is unreasonable, and the phenomenon of "empty nest" has appeared. My country is about to enter the stage of population aging. Most of the rural labor force in rural areas has moved to cities, causing the phenomenon of "empty nest elderly" in rural areas. In addition, because of the strict household registration system, the children of migrant workers are more educated. Difficult, leading to the phenomenon of "left-behind children". The old people in the rural areas are not supported by their children, and the children in the rural areas are not supported by their parents. This has resulted in the unreasonable structure of rural families and the unreasonable social demographic structure.

Second, the transfer of rural labor has led to an insufficient supply of labor in rural areas. The large-scale transfer of rural surplus labor has, on the one hand, caused a decline in the utilization rate of arable land. The area of arable land has been drastically reduced. However, the emergence of this situation has also accelerated China's implementation of rural land contract management and provided a broad space.

Third, the loss of a large number of rural labor forces has made it difficult to fundamentally eliminate the dual economic structure of China's urban and rural areas. The rapid development of China's economy is to a certain extent derived from the advantages of China's large amount of cheap labor. Under this circumstance, as long as you pay a higher wage than the rural income level, you can have a large number of cheap labor and absorb a large amount of cheap labor. The rural surplus labor force transfers from rural to urban [12]. The loss of a large number of rural labor forces is not only detrimental to the development of the primary industry, but even affects the development of the secondary and tertiary industries, and hinders their development to a certain extent.

Fourth, the continuous influx of rural laborers into cities has increased the burden on local and urban governments. On the one hand, the influx of rural labor into the cities, so a large number of left-behind children, left-behind women, empty-nest elderly caused by education, rescue, disputes, medical care, medical insurance and other issues caused the government to continue to increase the burden; on the other hand, the rural population continues to increase The influx of people into cities has increased the employment pressure of the urban population, and the urban population has grown overloaded. The damage to the urban environment and ecology is irreversible, which increases government expenditures and burdens the government. Finally, due to the continuous influx of rural population into cities, the phenomenon of "empty villages" has emerged, and rural public security problems have deteriorated, and the theft of private and shared property of villagers has become more serious.

\section{Countermeasures to the Problem of the Loss of Rural Labor}

To solve the problem of rural population loss and labor transfer, the main idea is to enable the rural areas to retain people, retain labor, and make villagers voluntarily stay at home. To put it bluntly, it means that villagers can earn money and be able to make a difference. Guarantee, can have a comfortable living environment, so personal views should be strengthened from the following aspects.

First, strengthen skills training for rural villagers and improve the education level of rural left-behind children. Combining the actual situation of the rural labor force, the rural labor force is trained in technology and skills according to local conditions, so that the rural labor force can really master several skills, and the rural labor force is transformed from a physical type to a technical, knowledge-based, and skilled talent, so as to make up for the modern The problem of insufficient technology in rural areas.

Second, strengthen rural infrastructure construction and increase investment in social undertakings. Strengthening the construction of rural infrastructure is mainly aimed at rural transportation. In some rural areas, the transportation is not convenient. It is difficult for people from outside to get in and people from the village to get out. This restricts the progress of rural commerce and economic development. To strengthen the construction of rural infrastructure, we must first realize the construction of rural roads, so that the road to the countryside is convenient and quick enough. Increase investment in social undertakings, establish a basic production, basic life, and basic medical security system for farmers, and strengthen the construction of rural culture, sports and other facilities, so that the spiritual and cultural life of rural farmers is continuously enriched and developed.

Third, encourage the development of township and village enterprises, and continuously strengthen the construction of township and village enterprises. Strengthen the ideological construction of migrant rural laborers, encourage and support some migrant workers who are willing to return to their hometowns to set up enterprises to start businesses back home, provide certain policy support and preferential policies, and increase the rural employment rate by strengthening the construction and development of township enterprises, To promote urbanization and industrialization in rural areas, so as to realize "to enter the factory without entering the city, and to 
leave the land without leaving the hometown."

Fourth, speed up land circulation and encourage large-scale operations. Use the government's funds for rural projects to a knife's edge, encourage rural people to explore and try land intensive and integrated management, speed up the circulation of land, and transfer the land to large growers or relatively capable business owners through land. The large-scale operation of the land will increase the utilization rate of land and the rationality of its use. At the same time, it will increase the employment rate in rural areas, which will help local rural residents solve the employment problem.

Fifth, strengthen the construction of the rural education system and improve the general education level of rural children. First, strengthen the construction of the rural education system. In some rural areas, the educational environment is relatively simple, with a certain degree of lack of software and hardware facilities, and the teaching staff is relatively weak, which does not give children a good education environment. Strengthen the construction of the education system, guide children to actively learn cultural knowledge, master certain skills and technologies, and lead children to grow up healthily, so that they can contribute their own strength to the construction of their hometown when they grow up.

\section{The Significance of Solving the Problem of the Loss of Rural Labor}

First, to solve the problem of the loss of rural labor force can better implement the strategy of rural revitalization and solve the "three rural issues" to a certain extent. my country is essentially a large agricultural country with rural characteristics. The essence of my country's culture is also rural, and the countryside is the source and carrier of rural culture. China has a large rural population and vast rural land. If we want to achieve an all-round well-off and thoroughly win the battle against poverty, we must implement the strategy of rural revitalization, solve the "three rural issues", and make agriculture progress, rural development, and farmers happy.

Second, solving the problem of the loss of rural labor can to a certain extent eliminate the phenomenon of empty-nest elderly and left-behind children. The large-scale transfer of rural labor force has resulted in the phenomenon of "empty villages", which makes rural elderly people unable to support their children, and rural medical and health facilities are not perfect, and the social security system is not perfect. They have not done their best for the elderly in their later years. Children should fulfill their responsibilities; and the phenomenon of "left-behind" children, children of rural laborers who go out to work, cannot follow their parents to go out to work because of the strict household registration system. They can only stay in the left-behind home without the care and care of parents. Can not give their children a healthy growth space, failing to fulfill their responsibilities as parents. Third, to solve the problem of the loss of rural labor force and at the same time solve the problem of food security in our country is a powerful way to keep the Chinese people's rice bowl firmly in their own hands. Since ancient times, China has been a big agricultural country with a large population. As the old saying goes, people rely on food as their heaven, and food security has always been the foundation of national security. General Secretary Xi Jinping also said that we must attach importance to national food security and keep the Chinese people's rice bowl firmly in their own hands. That is to let food production and agricultural development be the core of agricultural production, and the purpose of the rural revitalization strategy is to make agriculture develop vigorously. A bumper harvest of grain [13]. To ensure that the bottom line of China's 1.8 billion mu of arable land cannot be breached, and to fundamentally solve the problem of China's food security, and no longer be dominated and controlled by the national agricultural product market, so that the Chinese people's rice bowl is firmly in their own hands.

\section{Conclusion}

This article mainly studies and discusses the problems of population loss and labor transfer in rural areas under the rural revitalization strategy. Solving the "three rural issues" is of epochal significance, and it also conforms to the needs of the development of the times, and is also an important prerequisite for building my country into a powerful modern socialist country. Based on the just-convened Fifth Plenary Session of the 19th Central Committee, this year is the final year for the fight against poverty. The rural revitalization strategy is an indispensable part. Rural development and agricultural revitalization are the necessary prerequisites for the country's modernization and development. Without the development of the countryside, the progress of agriculture, and the prosperity of farmers, it will inevitably hinder our country's progress in achieving an all-round well-off society and eradicating poverty. To effectively implement urban-rural integration and promote the process of rural urbanization and modernization, it is necessary to continuously strengthen the construction of rural infrastructure, encourage the development of township enterprises, continuously strengthen the training of farmers, reduce the loss of rural labor, and continue to absorb high-quality talents to assist in the development of the countryside. Therefore, for China's development and for the great rejuvenation of the Chinese nation, the rural revitalization strategy has extremely important significance.

\section{References}

[1] Fei Xiaotong. Rural China [M]. Shanghai: East China Normal University Press, 2018.

[2] Ma Xiaohe, Hu Yongjun. Research on the problem of urbanization of 100 million agricultural transfer population[J]. Agricultural Economic Issues. 2018 (04): 4-14.

[3] Wei Houkai, Su Hongjian. Research on the process of urbanization of China's agricultural transfer population[J]. China Population Science. 2013(5): 21-29. 
[4] Xiang Jing, Zhong Funing. Rural population transfer, industrialization and urbanization $[\mathrm{J}]$. Agricultural Economic Issues. 2018 (12): 51-56.

[5] Huang Zuhui. Accurately grasp China's rural revitalization strategy [J]. China Rural Economy. 2018 (04): 2-12.

[6] Wang Fayuan et al. Research on characteristic agriculture development under the background of rural revitalization strategy $[\mathrm{M}]$. Beijing: China Agriculture Press, 2018.

[7] Zhang Dengguo. Grassroots governance and Rural revitalization: the action paradigm of the first secretary of youth [J]. Chinese Youth Studies, 2019(09): 25-30.

[8] Yu Jianrong. The revitalization of rural industries should be adapted to local conditions[J]. People's Forum, 2018(17): 64-65.

[9] Qi Wei, Liu Shenghe, Jin Fengjun. Research on the prediction and evolution pattern of population loss in the three northeastern provinces[J]. Geographical Sciences, 2018 (02): 01-11.

[10] Hu Jiliang, Chen Yao. Analysis on the cultivation of characteristic industries for precision poverty alleviation-A case study of Zhuxi County in Qinba Mountains [J]. Journal of South-Central University for Nationalities (Humanities and Social Sciences Edition), 201838(04): 166-170.

[11] Xuan Jing. Research on rural revitalization strategy from the perspective of Marxist urban-rural relationship theory [D]. Lanzhou: Northwest University for Nationalities, 2020.

[12] Zhang Yanman. Research on the urban-rural integration development system with Chinese characteristics in the new era [D]. Changchun: Jilin University, 2020.

[13] Ye Xingqing. Rural revitalization strategy in the New Era [J]. Reform, 2018 (1): 65-73.

\section{Author Profile}

Shidong Zhang (1996-), Graduate student of School of Economics and Management, Zhejiang Ocean University. Born in Luoyang, Henan Province, the professional name is Rural Development. 